\title{
Experimental dehydration of wet fibrous materials
}

\author{
Gayrat Bahadirov ${ }^{2 *}$, Takhirjon Sultanov ${ }^{1}$, Gerosim Tsoy ${ }^{2}$, and Ayder Nabiev ${ }^{2}$ \\ ${ }^{1}$ Tashkent Institute of Irrigation and Agricultural Mechanization Engineers, Tashkent, Uzbekistan, \\ ${ }^{2}$ Institute of Mechanics and Seismic Stability of Structures of the Academy of Sciences of the \\ Republic of Uzbekistan, Tashkent, Uzbekistan
}

\begin{abstract}
The article presents the results of experimental studies to substantiate the performance of the method of simultaneous extracting excess moisture from wet leather semi-finished products. In the experiment, the influence of the feeding speed, the pressing force of the squeezing rollers on the amount of moisture removed from two layers of the leather semi-finished product after their squeezing was determined. The experiment was conducted using a moisture-removing material - a BM brand monchon, laid on a guide bar, on which two layers of the wet leather semi-finished product were previously folded. A monchon of the LASCH brand is folded between the layers of a semi-finished leather product. Due to the flexibility of the monchon, the displacement of semi-finished leather products movement path along the conveying device is reduced.
\end{abstract}

\section{Introduction}

The study in[1] describes the current trend in applying vegetable tanning technology and wet processing methods based on new solvents, ionic and other liquids when solving the problem of using chromium in the leather industry. In [2-11], the influence of the technology of liquid, chemical, and mechanical treatment on the properties of leather collagens and its deformation and filtration parameters was studied. In [12], a review of 39 peer-reviewed articles in English devoted to the study of leather processing is given, of which 30 articles were published in the last 6 years. These publications are devoted to the following areas: research of the general cycle of leather production, individual process research, waste treatment, and recycling technologies, and long-term strategy ideas for the leather industry. Research in [13-21] is devoted to improving and analyzing the designs of roller squeezing machines that contribute to increasing labor productivity and efficiency of technological processes for processing sheet and fibrous materials.

In the current article, the operability and efficiency of the method were experimentally investigated; instead of a metal base plate, a moisture-removing material of the BM brand was used in the form of an infinite cloth, bent on a metal guide bar, on which two layers of the wet leather semi-finished product were laid with moisture-removing materials of the

\footnotetext{
* Corresponding author: instmech@rambler.ru,
} 
LASCH brand; they were vertically fed between rotating squeezing rollers, covered by one layer of moisture-removing material of the BM brand [7].

\section{Materials and methods}

The experiment was conducted on a special test bench, where the squeezing rollers were mounted horizontally, where a moisture-removing material of the BM brand was used instead of a base plate in the form of an infinite strip $0.01 \mathrm{~m}$ thick, bent on a metal guide bar, $0.1 \mathrm{~m}$ wide and $0.3 \mathrm{~m}$ long. Figure 1 shows a diagram of the implementation of the method of moisture extraction from wet leather semi-finished products.

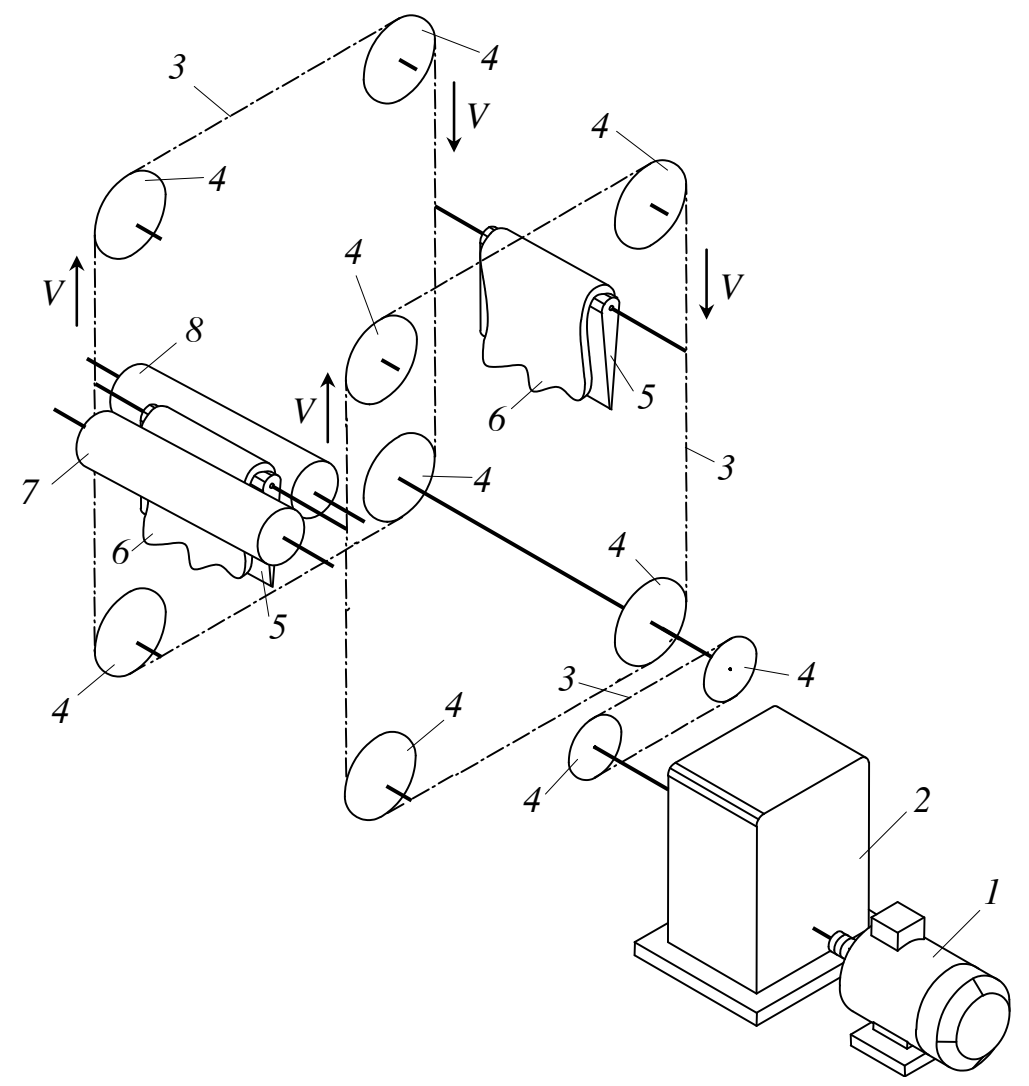

Fig. 1. Structural scheme of the experimental bench for squeezing excess moisture from the semifinished leather product: 1 is electric motor; 2 is reduction gear; 3 is chain; 4 are sprockets; 5 is BM monshon; 6 is semi-finished leather product; 7, 8 are squeezing rollers

The material of the semi-finished leather product for the experiment was a mediumweight bovine hide after chrome tanning, splitted. According to the International Standards ISO 2588-85, the required number of samples of the semi-finished leather product was determined according to the following formula

$$
n=0.2 \sqrt{x}
$$


where $\mathrm{x}$ is the number of the semi-finished leather products for the experiment, 2500 pieces, $\mathrm{n}=10$ pieces. The strips $0.05 \times 0.25 \mathrm{~m}$ from these 10 semi-finished leather products were cut out with a cutter across the spine line and numbered; the strips were assembled into groups of 5 pcs according to the scheme given in [22]-[24]. After that, the stand was turned on, the compression of the springs was calibrated to the desired pressure, an autotransformer controlled the speed, and the clock-type tachometer TCh10P regulated the rotational speed of the rollers. Preliminarily, control samples of the semi-finished leather product were fed, and then the compression of the springs was measured, i.e., the deviation from the set values. If the deviation exceeded $3 \%$, then the compression of the springs was adjusted by tightening the nuts. Then the basic samples were fed. They were weighed on VLTE-500 laboratory scales before and after squeezing; the resolution was $0.01 \mathrm{~g}$ (ISO9001).

When processing the experimental results, the method of D-optimal planning of the second order was used applying the $\mathrm{K}$. Kano design matrix, which provides the highest accuracy in the estimates of the regression coefficients [22-24]. It was taken into account that Kano's design matrix provides for a variety of factors at three levels: lower $(-)$, zero $(0)$, and upper $(+)$ levels, which is appropriate for this study. Based on a priori information, the process of liquid removal was studied, taking into account two factors: $x_{1}$ is the pressure intensity $P, \mathrm{kN} / \mathrm{m} ; x_{2}$ is the feeding speed, $V, \mathrm{~m} / \mathrm{s}$. The range of pressure change was from 32 to $96 \mathrm{kN} / \mathrm{m}$; the speed of squeezing rollers - from 0.17 to $0.34 \mathrm{~m} / \mathrm{s}$ obtained in the analysis of roller squeezing machines made in different countries. In the study, the diameter of the squeezing rollers was $0.2 \mathrm{~m}$, and the coating from BM cloth was $0.01 \mathrm{~m}$ thick.

The required number of measurements (the number of replicates) was selected before the experiment, using the methods of mathematical statistics, which provided the required accuracy.

The working matrix was drawn up according to the K. Kano design matrix for a twofactor experiment. Factors were encoded according to the following formula

$$
x_{i}=\frac{c_{i}-c_{i 0}}{t_{0}}
$$

where $\mathrm{xi}$ is the encoding of the factor value; ci, ci0 are the natural values of the factor at the current and zero levels; t0 is the natural value of the factor variation range. The levels and ranges of variation of the experimental factors are given in table 1.

Table 1

\begin{tabular}{|c|c|c|c|}
\hline \multirow{2}{*}{ Index } & Coded value of factors & \multicolumn{2}{|c|}{ Natural values of factors } \\
\cline { 2 - 4 } & & $x_{1}, \mathrm{kN} / \mathrm{m}$ & $x_{2}, \mathrm{~m} / \mathrm{s}$ \\
\hline Upper level & + & 96 & 0.340 \\
\hline Zero level & 0 & 64 & 0.255 \\
\hline Lower level & - & 32 & 0.170 \\
\hline \multicolumn{2}{|c|}{ Variation interval } & 32 & 0.085 \\
\hline
\end{tabular}

The chain function is approximated by the polynomial

$$
y=b_{0}+\sum_{i=1}^{k} b_{i} x_{i}+\sum_{i, j=1}^{k} b_{i j} x_{i} \cdot x_{j}+\sum_{i=1}^{k} b_{i i} x_{i}^{2}
$$

where $y$ is the amount of moisture removed in coded form; $b_{0}, b_{i}, b_{i j}, b_{i i}$ are the regression coefficients. 
The measurement results before and after the moisture extraction from the first and second layers of the leather semi-finished product at different values of the pressing force $x_{1}(P)$ and the feeding speed $x_{2}(V)$ are shown in Table 2.

Table 2

\begin{tabular}{|c|c|c|c|c|c|c|c|c|}
\hline \multirow{2}{*}{ № } & \multirow{2}{*}{$\begin{array}{l}P, \\
x_{1}\end{array}$} & \multirow{2}{*}{$\begin{array}{l}V, \\
x_{2} \\
\end{array}$} & \multicolumn{2}{|c|}{$y_{1}, g r$} & \multicolumn{2}{|c|}{$y_{2}, g r$} & \multicolumn{2}{|c|}{$y_{3}, g r$} \\
\hline & & & $y_{s t 1}$ & $y_{f i n 1}$ & $y_{s t 2}$ & $y_{\text {fin } 2}$ & $y_{s t 3}$ & $y_{f i n 3}$ \\
\hline \multirow{2}{*}{1} & \multirow{2}{*}{0} & \multirow{2}{*}{0} & 98.9 & 66.9 & 70.2 & 51.4 & 71.2 & 50.0 \\
\hline & & & 83.2 & 62.3 & 93.7 & 70.4 & 87.6 & 66.8 \\
\hline \multirow{2}{*}{2} & \multirow{2}{*}{+} & \multirow{2}{*}{+} & 84.1 & 65.5 & 93.6 & 65.7 & 88.1 & 64.0 \\
\hline & & & 75.1 & 51.9 & 79.2 & 59.4 & 87.4 & 61.5 \\
\hline \multirow{2}{*}{3} & \multirow{2}{*}{-} & \multirow{2}{*}{+} & 90.8 & 69.2 & 71.0 & 57.6 & 89.2 & 68.0 \\
\hline & & & 93.8 & 72.6 & 75.4 & 61.4 & 90.1 & 63.8 \\
\hline \multirow{2}{*}{4} & \multirow{2}{*}{-} & \multirow{2}{*}{ - } & 86.6 & 61.8 & 80.2 & 56.4 & 73.5 & 54.0 \\
\hline & & & 96.5 & 72.2 & 72.6 & 54.5 & 72.4 & 52.3 \\
\hline \multirow{2}{*}{5} & \multirow{2}{*}{+} & \multirow[b]{2}{*}{-} & 78.5 & 52.5 & 72.2 & 43.5 & 79.3 & 48.5 \\
\hline & & & 97.4 & 66.7 & 97.8 & 62.4 & 89.7 & 58.1 \\
\hline \multirow{2}{*}{6} & \multirow{2}{*}{+} & \multirow{2}{*}{0} & 73.6 & 48.2 & 72.6 & 51.3 & 86.8 & 54.3 \\
\hline & & & 84.2 & 58.9 & 71.6 & 51.7 & 96.8 & 66.0 \\
\hline \multirow{2}{*}{7} & \multirow{2}{*}{0} & \multirow{2}{*}{+} & 84.2 & 60.0 & 90.3 & 65.1 & 91.3 & 68.0 \\
\hline & & & 62.7 & 45.8 & 77.5 & 55.2 & 95.2 & 66.2 \\
\hline \multirow{2}{*}{8} & \multirow{2}{*}{ - } & \multirow{2}{*}{0} & 66.7 & 49.4 & 83.3 & 61.0 & 93.8 & 66.0 \\
\hline & & & 77.2 & 50.2 & 97.5 & 72.5 & 65.0 & 41.7 \\
\hline \multirow{2}{*}{9} & \multirow{2}{*}{0} & \multirow{2}{*}{-} & 79.0 & 55.5 & 95.3 & 68.5 & 85.3 & 52.3 \\
\hline & & & 95.0 & 68.0 & 89.2 & 59.4 & 69.8 & 48.5 \\
\hline
\end{tabular}

Table 2 continued

\begin{tabular}{|c|c|c|c|c|c|}
\hline \multirow{2}{*}{ № } & \multicolumn{2}{|c|}{$y_{4}, g r$} & \multicolumn{2}{|c|}{$y_{5}, g r$} & \multirow{2}{*}{$\begin{array}{c}\text { № of samples } \\
\text { leather }\end{array}$} \\
\hline & $y_{s t 4}$ & $y_{\text {fin } 4}$ & $y_{s t 5}$ & $y_{f i n}$ & \\
\hline \multirow{2}{*}{1} & 82.7 & 60.9 & 93.3 & 66.3 & 1 \\
\hline & 84.5 & 52.6 & 80.6 & 59.9 & 2 \\
\hline \multirow{2}{*}{2} & 71.6 & 53.3 & 76.7 & 51.8 & 1 \\
\hline & 77.0 & 55.4 & 96.0 & 69.1 & 2 \\
\hline \multirow{2}{*}{3} & 77.6 & 59.8 & 64.9 & 49.4 & 1 \\
\hline & 83.3 & 64.6 & 81.9 & 65.8 & 2 \\
\hline \multirow{2}{*}{4} & 74.5 & 53.3 & 83.9 & 62.3 & 1 \\
\hline & 78.3 & 55.7 & 76.7 & 59.1 & 2 \\
\hline \multirow{2}{*}{5} & 81.4 & 52.5 & 98.0 & 57.7 & 1 \\
\hline & 77.5 & 53.2 & 89.2 & 59.2 & 2 \\
\hline \multirow{2}{*}{6} & 72.9 & 51.8 & 72.2 & 50.8 & 1 \\
\hline & 84.2 & 62.4 & 96.5 & 59.4 & 2 \\
\hline \multirow{2}{*}{7} & 71.2 & 50.8 & 91.0 & 64.8 & 1 \\
\hline & 78.9 & 60.8 & 92.6 & 68.2 & 2 \\
\hline \multirow{2}{*}{8} & 70.6 & 54.2 & 89.0 & 65.1 & 1 \\
\hline & 86.3 & 58.1 & 70.5 & 51.8 & 2 \\
\hline \multirow{2}{*}{9} & 94.3 & 66.0 & 72.0 & 52.5 & 1 \\
\hline & 76.6 & 54.1 & 91.9 & 60.8 & 2 \\
\hline
\end{tabular}

$y_{s t}$ is the initial weight of a sample of wet leather semi-finished product;

$y_{\text {fin }}$ is the weight of a sample of semi-finished leather product after pressing.

After the implementation of the working matrix, the arithmetic mean values were 
obtained (Table 3).

Table 3

\begin{tabular}{|c|c|c|c|c|c|c|c|c|c|}
\hline \multirow{2}{*}{ № } & \multirow{2}{*}{$\begin{array}{l}P, \\
x_{1}\end{array}$} & \multirow{2}{*}{$\begin{array}{l}V, \\
x_{2}\end{array}$} & \multirow{2}{*}{$\begin{array}{l}\text { № of } \\
\text { leath. } \\
\text { prod. }\end{array}$} & \multicolumn{6}{|c|}{ Measurement results, \% } \\
\hline & & & & $y_{1}$ & $y_{2}$ & $y_{3}$ & $y_{4}$ & $y_{5}$ & $\bar{y}$ \\
\hline \multirow{2}{*}{1} & \multirow{2}{*}{0} & \multirow{2}{*}{0} & 1 & 32.4 & 26.8 & 29.7 & 26.3 & 28.9 & 28.8 \\
\hline & & & 2 & 25.1 & 24.9 & 23.7 & 37.7 & 25.7 & 27.4 \\
\hline \multirow{2}{*}{2} & \multirow{2}{*}{+} & \multirow{2}{*}{+} & 1 & 22.1 & 29.8 & 27.4 & 25.3 & 32.5 & 30.4 \\
\hline & & & 2 & 30.9 & 25.0 & 30.4 & 28.0 & 28.0 & 28.9 \\
\hline \multirow{2}{*}{3} & \multirow{2}{*}{-} & \multirow{2}{*}{+} & 1 & 23.8 & 18.9 & 26.0 & 22.9 & 23.9 & 23.1 \\
\hline & & & 2 & 22.6 & 18.6 & 29.2 & 22.5 & 19.6 & 22.5 \\
\hline \multirow{2}{*}{4} & \multirow{2}{*}{-} & \multirow{2}{*}{-} & 1 & 28.6 & 29.7 & 26.4 & 32.5 & 25.8 & 28.6 \\
\hline & & & 2 & 25.2 & 25.0 & 27.7 & 28.9 & 22.9 & 26.2 \\
\hline \multirow{2}{*}{5} & \multirow{2}{*}{+} & \multirow{2}{*}{-} & 1 & 33.2 & 39.8 & 38.8 & 35.5 & 41.1 & 37.7 \\
\hline & & & 2 & 31.5 & 36.2 & 35.2 & 31.4 & 33.6 & 33.6 \\
\hline \multirow{2}{*}{6} & \multirow{2}{*}{+} & \multirow{2}{*}{0} & 1 & 34.2 & 29.4 & 37.4 & 28.9 & 29.6 & 31.9 \\
\hline & & & 2 & 30.1 & 27.8 & 31.8 & 25.9 & 38.4 & 30.8 \\
\hline \multirow{2}{*}{7} & \multirow{2}{*}{0} & \multirow{2}{*}{+} & 1 & 28.7 & 27.9 & 25.5 & 28.7 & 28.7 & 27.9 \\
\hline & & & 2 & 27.0 & 28.8 & 30.5 & 23.0 & 26.4 & 27.1 \\
\hline \multirow{2}{*}{8} & \multirow{2}{*}{-} & \multirow{2}{*}{0} & 1 & 26.0 & 26.8 & 29.6 & 23.4 & 26.8 & 26.5 \\
\hline & & & 2 & 35.0 & 25.6 & 35.9 & 32.7 & 26.5 & 25.2 \\
\hline \multirow{4}{*}{9} & \multirow{2}{*}{0} & \multirow{2}{*}{-} & 1 & 29.8 & 28.1 & 38.7 & 30.0 & 27.1 & 31.7 \\
\hline & & & 2 & 28.4 & 33.4 & 30.5 & 29.4 & 33.8 & 31.1 \\
\hline & & & 1 & & & & & & \\
\hline & & & 2 & & & & & & \\
\hline
\end{tabular}

Table 3 continued

\begin{tabular}{|c|c|c|c|c|c|}
\hline \multirow{2}{*}{$№$} & $\sum_{1}^{n}(y-\bar{y})^{2}$ & $S_{e r}^{2}$ & $\hat{y}_{\text {cal }}$ & $\bar{y}-\hat{y}_{\text {cal }}$ & $\left(\bar{y}-\hat{y}_{\text {cal }}\right)^{2}$ \\
\hline \multirow{2}{*}{1} & 24.03 & 6.0 & 28.9 & 0.1 & 0.01 \\
\cline { 2 - 6 } & 131.32 & 32.8 & 28.3 & 0.9 & 0.81 \\
\hline \multirow{2}{*}{2} & 108.67 & 27.2 & 29.2 & 0.6 & 0.36 \\
\cline { 2 - 6 } & 35.08 & 8.8 & 27.4 & 1.5 & 2.25 \\
\hline \multirow{2}{*}{3} & 34.02 & 8.5 & 23.4 & 0.3 & 0.09 \\
\cline { 2 - 6 } & 24.12 & 6.0 & 23.5 & 1.0 & 1.0 \\
\hline \multirow{2}{*}{4} & 29.1 & 7.3 & 28.6 & 0 & 0 \\
\cline { 2 - 6 } & 22.87 & 7.3 & 27.3 & 1.1 & 1.21 \\
\hline \multirow{2}{*}{5} & 42.27 & 10.6 & 35.7 & 2.0 & 4.0 \\
\cline { 2 - 6 } & 18.57 & 4.6 & 31.6 & 2.0 & 4.0 \\
\hline \multirow{2}{*}{6} & 55.2 & 13.8 & 31.9 & 0 & 0 \\
\cline { 2 - 6 } & 92.26 & 23.1 & 30.2 & 0.6 & 0.36 \\
\hline \multirow{2}{*}{7} & 92.26 & 23.1 & 26.5 & 1.4 & 2.56 \\
\cline { 2 - 6 } & 31.12 & 7.8 & 25.8 & 2.1 & 4.41 \\
\hline \multirow{2}{*}{8} & 14.45 & 3.6 & 25.5 & 1.0 & 1.0 \\
\cline { 2 - 6 } & 267.17 & 6.5 & 26.1 & 0.9 & 0.81 \\
\hline \multirow{2}{*}{9} & 121.62 & 30.4 & 32.3 & 0.6 & 0.36 \\
\cline { 2 - 6 } & 29.52 & 7.4 & 29.6 & 1.5 & 2.25 \\
\hline & $\Sigma 521.62$ & $\Sigma 130.4$ & & & $\Sigma 8.38$ \\
\hline & $\Sigma 652.03$ & $\Sigma 163.0$ & & & $\Sigma 17.1$ \\
\hline
\end{tabular}


After the working matrix implementation, the arithmetic mean values were obtained (Table 2). The homogeneity of variance was checked using the Cochran test with a probability $\alpha=0.95$. Knowing the total number of variance estimates $N$ and the number of degrees of freedom $f=n-1$, we determiner $G_{\mathrm{T}}=0.358$ according to the table given in [22-22].

$$
\begin{aligned}
& G_{c a l_{1}}=\frac{S_{\max }^{2}}{\sum_{1}^{N} S_{i}}=\frac{30.4}{130.4}=0.233<G_{T}=0.358 \\
& G_{c a l_{2}}=\frac{32.8}{163.0}=0.201<G_{T}=0.358
\end{aligned}
$$

Thus, we have verified the condition for the reproducibility of the experimental results using the Cochran criterion; the calculated experimental values of the Cochran coefficients are less than the ones given in the table. Consequently, the condition for the reproducibility of the experimental results is met.

\section{Results and discussion}

Let us determine the regression coefficients $b_{0}, b_{\mathrm{i}}, b \mathrm{ij}, b_{\mathrm{ii}}$ from the table given in [22-24].

For the first layer of the semi-finished leather product, the coefficients are $b_{0}=28.9057$; $b_{11}=0.1788 ; b_{22}=0.5206 ; b_{1}=3.2160 ; b_{2}=-2.9198 ; b_{12}=0.325$.

For the second layer of the semi-finished leather product, the coefficients are $b_{0}=28.3098$;

$b_{11}=-0.1671 ; b_{22}=-0.6202 ; b_{1}=2.0045 ; b_{2}=1.8942 ; b_{12}=-0.15$

The regression equation in a coded form is:

for the first layer of the semi-finished leather product

$$
y_{1}=28.9057+0.17885 x_{1}^{2}+0.5206 x_{2}^{2}+3.2160 x_{1}-2.9197 x_{2}-0.325 x_{1} x_{2}
$$

for the second layer of the semi-finished leather product

$$
y_{2}=28.3098-0.1671 x_{1}^{2}-0.6202 x_{2}^{2}+2.0045 x_{1}-1.8942 x_{2}-0.15 x_{1} x_{2}
$$

Substituting $x_{1}=\frac{P-64}{32}$, where $P$ is the pressing force of the squeezing rollers and $x_{2}=\frac{V-0.255}{0.085}$, where $V$ is the feeding speed of wet leather semi-finished products between the rotating squeezing rollers, we obtain the equations of the amount of moisture removed from wet leather semi-finished products between the rotating squeezing rollers in natural form.

The hypothesis about the adequacy of the equations obtained was tested using the Fisher criterion at a confidence level of $\alpha=0.95$ [22-24]

$$
F_{c a l}=\frac{S_{a d}^{2}}{S^{2}\{y\}}<F_{T}
$$


where $S_{a d}^{2}$ is the residual variance or the variance of adequacy; $S_{\{y\}}^{2}$ is the variance reproducibility.

$S_{a d}^{2}$ and $S_{\{y\}}^{2}$ were determined from tables 1 and 2 as follows:

$$
\begin{aligned}
& s_{\text {ad }}^{2}=\frac{\sum_{1}^{N} n(\bar{y}-\hat{y})^{2}}{\frac{N-(x+2)(x+1)}{2}} \\
& S_{\{y\}}^{2}=\frac{\sum_{1}^{N} \sum_{1}^{n}(y-\bar{y})^{2}}{N(n-1)}
\end{aligned}
$$

where $N$ is the total number of experiments; $k$ is the number of factors; $\mathrm{n}$ is the number of replicates in the experiment; $y$ is the result of a separate observation; $\bar{y}$ is the arithmetic mean values of the results of the experiment; $£$ are the calculated values of the criterion according to the regression equation.

For the first layer of the semi-finished leather product:

$$
\begin{aligned}
& S_{a d 1}^{2}=\frac{5 \cdot 8.38}{3}=13.97 ; S_{1}^{2}\{y\}=\frac{521.62}{36}=14.489 \\
& F_{\text {cal1 }}=\frac{13.98}{14.489}=0.964 ; F_{c a l 1}=0.0964<F_{T}=2.88
\end{aligned}
$$

For the second layer of the semi-finished leather product:

$$
\begin{aligned}
& S_{a d 2}^{2}=\frac{5 \cdot 17.1}{3}=28.5 ; S_{2}^{2}\{y\}=\frac{652.03}{36}=18.112 \\
& F_{\text {cal } 2}=\frac{28.5}{18.112}=1.574 ; F_{\text {cal } 2}=1.574<F_{T}=2.88
\end{aligned}
$$

So, the regression equation can be considered suitable with a $95 \%$ confidence level, which in the named form after decoding has the following form:

for the first layer of the semi-finished leather product:

$$
\Delta W_{1}=34.6127+0.0002199 P^{2}+114.2145 V^{2}+0.11525 P-81.2073 V-0.1654 P V,
$$

for the second layer of the semi-finished leather product:

$$
\Delta W_{2}=23.9648-0.0008857 P^{2}+76.0969 V^{2}+0.2590 P-55.721 V-0.1654 P V
$$

A graph of the dependence of the amount (in \%) of removed moisture $\Delta W$ from two layers of wet leather semi-finished products at different feeding speeds $V$ and pressing forces $P$ (Figure 2) is plotted. 


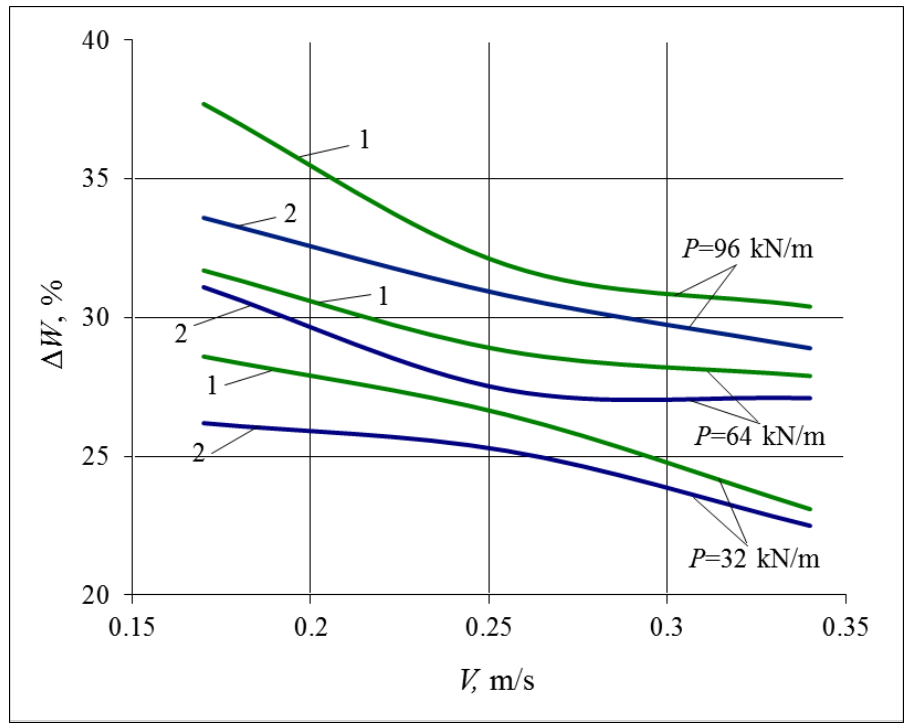

Fig. 2. Dependence of the amount of removed moisture $\Delta W$ on the feeding speed $V$ of the leather semi-finished products under the pressure of the squeezing rollers: 1 is the first layer of the semifinished leather product; 2 is the second layer of the semi-finished leather product

Thus, we have obtained regression equations for the dependence of the amount of removed moisture for the first (11) and second (12) layers of a semi-finished leather product on the feeding speed and the pressing force of the squeezing rollers.

The analysis of the experimental results obtained shows (Figure 2) that at the simultaneous squeezing of excess moisture from two layers of a wet leather semi-finished product using a flexible moisture-removing material - monchons of the BM brand, the efficiency of the technological process increases by approximately $2 \%$ compared to using a rigid base plate. The uniformity of moisture squeezing from the leather semi-finished product increases.

\section{Conclusions}

The results of the experiments show that the maximum moisture removal at the pressing pressure $P=96 \mathrm{kN} / \mathrm{m}$ of the squeezing rollers and the feeding speed $V=0.17 \mathrm{~m} / \mathrm{s}$ for the first layer of the leather semi-finished product averages $37.7 \%$ and for the second layer $33.6 \%$, depending on the initial weight of samples of the semi-finished leather product. The minimum amount of removed moisture at the pressing pressure of the rollers $P=32 \mathrm{kN} / \mathrm{m}$ and a feeding speed of the leather semi-finished products $V=0.34 \mathrm{~m} / \mathrm{s}$ for the first layer of leather semi-finished product is on average $23.1 \%$ and for the second layer $22.5 \%$, depending on the initial weight of samples of the leather semi-finished product. In the experiment, the amount of moisture removed over the required amount for the first layer of leather semi-finished product at different feeding speed and pressing force of the rollers is $10.1 \div 24.7 \%$, and for the second layer is $12.5 \div 19.6 \%$. These data allow us to conclude that it is possible to increase the feeding speed of the layers of leather semi-finished product to more than $0.34 \mathrm{~m} / \mathrm{s}$; therefore, it is possible to increase the productivity of the squeezing process of the roller machine. The results obtained from the experiment will be used in the design of a roller-squeezing machine with vertical feeding. 


\section{References}

1. Covington, A. D., Covington, T. Tanning Chemistry. The Science of Leather. (2009).

2. Danylkovych, A., Bilinskiy, S., Potakh, Y. Plasticification of leather semi-finished chrome tanning using biocatalitic modifier. EUREKA Phys. 1. p. 8-12. Eng. (2018).

3. Zhang, Y., Buchanan, J. K., Holmes, G., Mansel , B .W., Prabakar, S. Collagen structure changes during chrome tanning in propylene carbonate. J. Leather Sci. 1. p. 8. Eng. (2019).

5. Luo, F., Zhong, X., Gao, M., Peng, B., Long, Z. Progress and mechanism of breaking glycoconjugates by glycosidases in skin for promoting unhairing and fiber opening-up in leather manufacture. A review. J. Leather, 2. p. 12. Eng. (2020).

6. Preethi, S., Anumary, A., Ashokkumar, M., Thanikaivelan, P. Probing horseradish peroxidase catalyzed degradation of azo dye from tannery wastewater. Springerplus. 2. p. 341. (2013).

7. Amanov, A., Bahadirov, G., Amanov, T., Tsoy, G., Nabiev, A. Determination of Strain Properties of the Leather Semi-Finished Product and Moisture-Removing Materials of Compression Rolls. Materials (Basel). 12. p. 3620. (2019).

8. Liu, J., Luo, L., Hu, Y., Wang, F., Zheng, X., Tang, K. Kinetics and mechanism of thermal degradation of vegetable-tanned leather fiber. J. Leather Sci. 1. p. 9. Eng. (2019).

9. Fan, Q., Ma, J., Xu, Q., 2019. Insights into functional polymer-based organicinorganic nanocomposites as leather finishes. J. Leather Sci. 1. p. 3. Eng. (2019).

10. Zhang, X., Xu, S., Shen, L., Li, G. Factors affecting thermal stability of collagen from the aspects of extraction, processing and modification. J. Leather Sci. 2. p. 19. Eng. (2020).

11. Paiva, R. M., Marques, E. A., da Silva, L. F., Vaz, M.A. Importance of the surface treatment in the peeling strength of joints for the shoes industry. Appl. Adhes. Sci. (2013).

12. Tasca, A. L., Puccini, M. Leather tanning: Life cycle assessment of retanning, fatliquoring and dyeing. J. Clean. Prod. 226(720). p. 9. (2019).

13. Bahadirov, G. A., Sultanov, T. Z., Abdukarimov, A. Comparative analysis of two gear-lever differential inter-roller transmission mechanisms. IOP Conf. Ser. Earth Environ. Sci.p. 614. (2020).

14. Bahadirov, G. A., Sultanov, T. Z., Abdukarimov, A. Kinematic analysis of toothlever differential transmission mechanisms. IOP Conf. Ser. Earth Environ. Sci. (2020). 614(012101). (2020)

15. Bahadirov, G., Sultanov, T., Umarov, B., Bakhadirov, K. Advanced machine for sorting potatoes tubers. IOP Conf. Ser.: Mater. Sci. Eng. (2020). 883012132. DOI:10.1088/1757-899X/883/1/012132. (2020)

16. Mavlonov, T., Akhmedov, A., Saidakhmedov, R., Bakhadirov, K. Simulation modelling of cold rolled metal strip by asymmetric technology. IOP Conf. Ser. Mater. Sci. Eng. (2020). 883(012194).

17. Mehta, M., Naffa, R., Maidment, C., Holmes, G., Waterland, M. Raman and atr-ftir spectroscopy towards classification of wet blue bovine leather using ratiometric and chemometric analysis. J. Leather Sci. Eng. (2020).

18. Khusanov, K. Use the "Insert Citation" button to add citations to this document. of mechanical systems with nonholonomic servoconstraints. IOP Conf. Ser. Mater. Sci. Eng. (2020). 883 (012164). (2020).

19. Khusanov, K. Stabilization of mechanical system with holonomic servo constraints. IOP Conf. Ser. Mater. Sci. Eng. (2020). 883 (012146). (2020)

20. Rasulov, A. K., Nurmurodov, S. D., Bakhadirov, K. G., KHabibullayeva, I .A., 
Abdukarimova, S.B. Research and development of technology for hardening of rollers of the rolling mill. Test Eng. Manag. (2020).

21. Toshmatov, E., Akhmedov, A., Ibragimova, Z. Thermodynamic bases of mechanical working of metals by cutting. IOP Conf. Series: Materials Science and Engineering. (2020). 883. pp. 1-13. DOI:10.1088/1757-899X/883/1/012098. (2020)

22. Bahadirov, G., Tsoy, G., Nabiev, A. Study of the efficiency of squeezing moisturesaturated products. EUREKA Phys. 1. pp. 18-28. Eng. (2021).

23. Farooq, M. A., Nóvoa, H., Araújo, A., Tavares, S.M.O. An innovative approach for planning and execution of pre-experimental runs for Design of Experiments. Eur. Res. Manag. Bus. Econ. 22 (155-61). (2016).

24. Bahadirov, Gayrat, Ravutov, Shavkat, Abdukarimov, Abdusalam, Toshmatov, Elyor Development of the methods of kinematic analysis of elliptic drum of vertical-spindle cotton harvester. IOP Conference Series: Materials Science and Engineering. 1030 01216. pp. 1-13. DOI:10.1088/1757-899X/1030/1/012160. (2021). 